\title{
Address to the Conference of the South African Society of Physiotherapists, 8th October, 1955.
}

\author{
By DR. K. F. MILLS, Superintendent, Johannesburg General Hospital.
}

Madam, President and Members of the Society of Physiotherapists.

T NEED hardly say that I feel very honoured indeed at being invited to address you and to open this annual Conference of your Society. I also feel singularly unqualified to do so. Your Secretary, in inviting me to perform today, said that it was customary to invite a prominent member of the Medical Profession to stick his neck out on such occasions. I must however disclaim any such pretensions. My name, I regret to say appears very frequently in the Press, because not being in competitive clinical practice I do not incur the displeasure of the Medical Council whenever I am bullied or manoeuvred into making some more or less indiscreet statement about this or that or the other occurrence at this Hospital. I may therefore have acquired a certain notoriety, but by reason of not being in clinical practice my knowledge of modern Physiotherapy is probably just sufficient to be dangerous. So if I do stick my. neck out, I hope you will be charitable and resist the temptation to chop it off!

Now just about the time when I received your Secretary's invitation, I was engaged in reading a very long and much publicised novel in which one was taken with an almost painful degree of detail through the boyhood, college and hospital life and well on into the professional career of an earnest young American doctor. Surely, I thought, in so long a narrative I must find a few sidelights on physiotherapy and physiotherapists in the modern American professional world. But no! Then I read Richard Gordon's latest contribution to medical manners and customs, and I did find a passing reference to the "tickle and slap ladies," but he was clearly not really interested in them, and it was of course the night-nurse whom the hero of the story took off for a naughty weekend. Even in that treasury of light romance "The Woman's Weekly" you will find that the heroine of the current serial is either a nice young nurse, or a graceful young governess, or a ravishing young receptionist, or even a snappy young schoolmistress, but never, oh never, a pretty young physiotherapist! I wonder why.

Or, to consider a more serious type of fiction which is popularly considered to be the staple literary diet of the medical profession, I can recall dozens of ingenious stories in which the victim is disposed of in medico-legal fashion, varying from the crude administration of prussic acid to more subtle methods involving the induction of hypoglycaemic coma or even the engineering of an air embolism. But I have never yet read a thriller where the victim is found suspended by the neck on the kind of therapeutic gallows which you physiotherapists are wont, quite legitimately, to employ, nor is there any record, either in fact or fiction, of a bride being found drowned in a bubbly bath!

I don't know what conclusion to draw from all this, if indeed any valid conclusion can be drawn. I can only infer that the principles and practice of Physiotherapy are as yet so wrapped in mystery, that the writers of thrillers don't yet know and understand enough about its possibilities to exploit it; or maybe that Physiotherapists are so respectable, or perhaps so fierce, particularly when they operate with such terrifying equipment, that the writers of romance are positively scared off. How little they know.
When however we come away from the domain of fiction and fancy, we find that the physiotherapist is seen to occupy a very real and important place in our social organisation, and that the story of Physiotherapy abounds with interest and colour.

Physiotherapy in the abstract, that is the process of applying physical agencies to the relief of somatic disorder must have existed in the world as long as life itself has existed, and certainly as long as mankind. Heliotropism is a biological fact of practically all plant life, and an etiolated and sickly plant can, if the disorder has not progressed too far, be readily cured by a little judicious surgery followed by ample exposure to the rays of the sun.

Mankind, very early in its history, recognised comforting and healthgiving properties in the sun's rays, aeons before man began to have any conception of what the sun really was, or what was this mysterious influence which we now term radiation.

Naturally the sun, along with many other prominent and obvious natural phenomena, became deified and the object of worship to primitive man, and the Sun-God appears in the mythology of various races with many different names and in many different forms. To the ancient Greeks and Romans he was identified with Appollo, and he was always conventionally depicted as a very handsome young man, bursting with health and vitality. It is significant that Aesculapius, the God of Medicine in Greek mythology was conceived of as being the son of Appollo, and the first words of the original Hippocratic Oath, which governs our professional ethics to this day were: "I swear by Appollo the Healer ...."

Besides the rays of the Sun, the beneficial properties of many other physical agencies we e known to the ancients. Physical Culture and gymnastics formed the basis of rather more than half of the education of ancient Greek youth, and Hippocrates had, I believe, quite sound views on the use of massage in the treatment of fractures and dislocations. Maternal massage, in the treatment of infantile flatulence, $f$ probably has an even older root in history. It is customary in considering the History of Nursing to trace this back to the instincts of the primitive mother in caring for her child, and no doubt certain other physiotherapeutic techniques could also be traced to this source.

Electrotherapy was, I gather, discovered by accident about the time of the Emperor Nero, when some afflicted person paddling by the sea shore accidentally trod on an electric ray fish, and was dramatically cured of what ailed him. This incident must have caused quite a stir in the medical world of the time, and shocks from fish of this type apparently became quite a fashionable form of treatment for neuralgia and headaches. It was doubtless about this time that the armament with which the practitioner of Physical therapy is wont to surround himself or herself began to get so formidable! One wonders about the details of the technique of this form of electrotherapy. How did they manage to apply the fish without getting shocks themselves? It is a pity that it has gone out of fashion. One could imagine with relish the consternation and alarm of our Provincial Stores Organisation if presented with a rquisition for say-five dozen electric eels for use in the Physiotherapy Department of this Hospital. 
It is quite clear, I think, that the History of Physiotherapy is a fascinating subject, and you are all no doubt therapy is a fin it. But I think it is also true that the discoveries made by the ancients as to the beneficial effects of various made by thencies ran far in advance of the acquisition of knowledge as to how or why the application of these knowledge as the results that were found in practice agencies produced the rever that this empiricism persisted to occurtil quite recent times. One might say that the establishuntil quite recentotherapy as a profession coincided with and followed from the adoption of a scientific outlook in its practice.

But I would be so bold as to say that much that is empirical still persists here and there in the field of Physical Therapy as in other branches of Medicine.

I do not suppose that the ancient physicians who applied the electric shocks of the torpedo-fish came anywhere near a satisfactory explanation of what they were doing. They probably said that as physicians they were the divinely appointed representatives of Jupiter or Zeus, Father of Gods and Men, one of whose playful little prerogatives, you may remember, was to hurl thunderbolts right and left, and that they were, under his guidance and on his authority, just dispensing a few well-directed little thunderbolts, and so driving out the evil spirits responsible for their patients' disorders, whatever they were.

But, can the modern physician who turns on a switch, and hurls thunderbolts at his schizophrenic patients, via the medium of a shock-box, give a really satisfactory explanation as to how or why his therapy works and produces the results that it does? Can you explain in full and convincing details the rationale of ultra-sonic treatment, or even the benefits to be obtained from "taking the waters", internally or externally at Badplaats, Warmbaths, or even at some of the internationally renowned continental spas? You may refer to mechanical factors, chemical factors, thermal factors, or even psychological factors; but when you have said all that have you really explained?

There is surely much scope for scientific study and research in your profession, and in such study and research for co-operation and collaboration with fellow scientists in many and diverse fields of science, pure and applied.

And what of the future? Man has for countless ages contemplated the Universe around him, and speculated on the nature of matter. With remarkable intuition the philosophers of old stumbled on and held to a belief that things are not what they seem. Despite the evidence of their senses and contrary to all the dictates of common sense, they have continued throughout the ages to seek the philosopher's stone whereby the commonplace materials of their experience may be transmuted into fine gold. And now, modern Science has come along, and evolved theories and demonstrations to show that things are indeed not what they seem, and with a vengeance. Matter is now for the most part a manifestation of forces. The Universe is expanding at an explosive rate and dissolving into radiation, and to counterbalance this matter is continuously being created. Chemistry is becoming a branch of Physics, and Physics is assuming the position of queen among Sciences. The Philosopher's stone of the ancients is now seen to be as readily accessible as pebbles on the nearest beach. Transmutation of elements is an accomplished fact, with potentialities for the good or evil of the world as yet unestimated.

It is surely impossible to believe that in time, and it may well be sooner than we expect, the new Physics will not find an equally revolutionary expression in the practice of Medicine, and indeed in the field of Radiation Therapy that expression is already taking place. And it will surely follow that the Physiotherapy of today will give place tomorrow to new and powerful technical developments,

(Continued on page 7.)

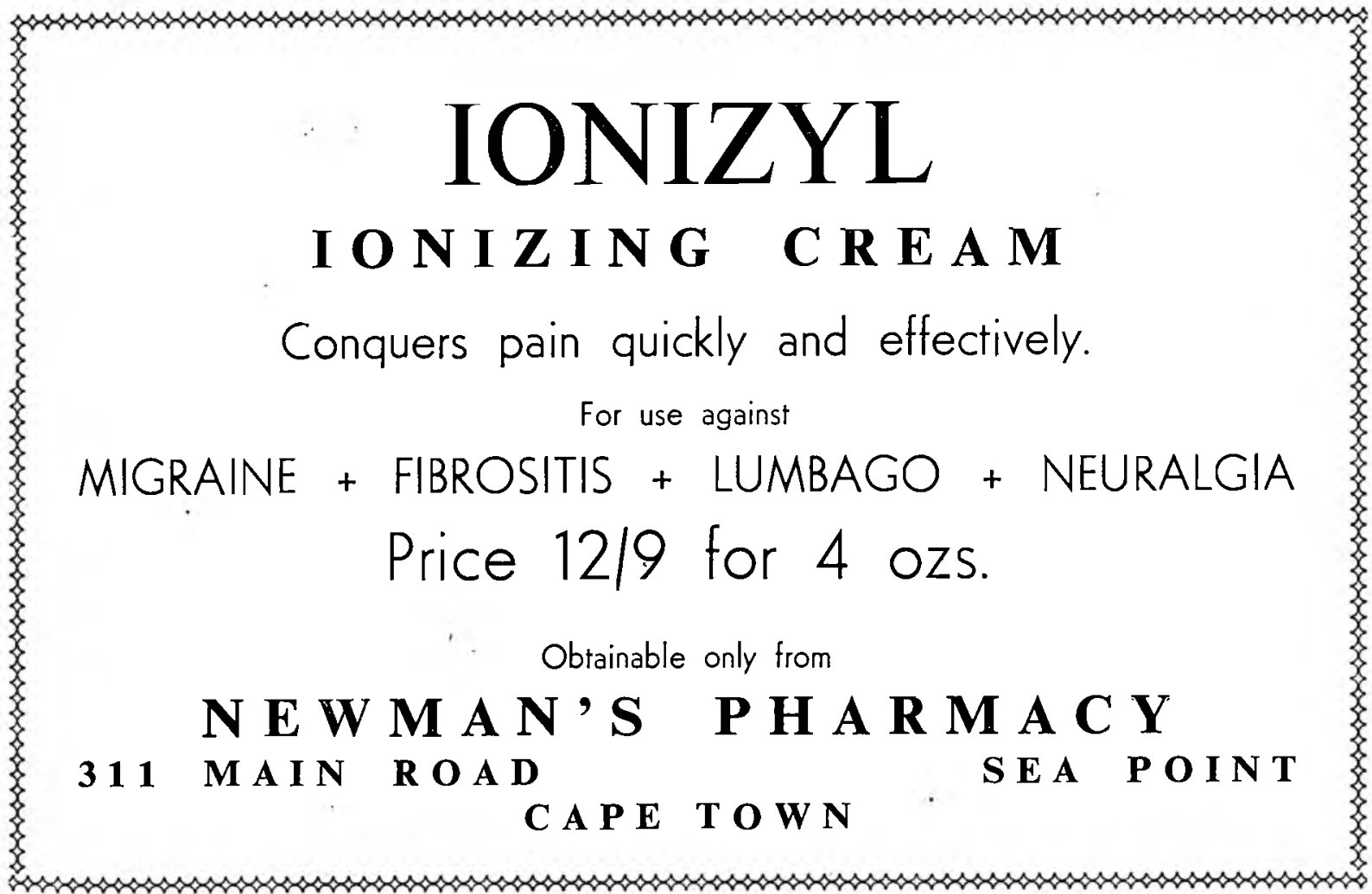




\section{GENERAL}

The following were successful in the B.Sc. (Physiotherapy) Rand examinations held in November:-

Miss C. Brest, Miss S. de Villiers, Miss L. Davids, Miss J. Feyder, Mrs. J. Finger, Miss H. Grosberg, Miss A. Jones, Miss B. Kaplan, Miss H. Mackay, Miss C. van der Spuy and Miss J. Wagner.

The following passed the examination for the Transvaal Physiotherapy Diploma at Pretoria Hospital:-

Miss E. Grunow, Miss F. Hitchcock, Miss M. Millar, Miss H. Morgan, Miss G. Silverman, Miss M. Slone, Miss L. Swart, Miss M. van Woudenberg, Miss A. van der Spek and Miss H. Wilson.

As several alterations have to be made to the renewed copy of the Private Practitioners Members' Register submitted at Conference, there will be some delay before it is printed in its final form. Any details from members who have not previously asked for inclusion on the register, must be sent to Mr. A. Rothberg, W.N.L.A., Eloff Street Extension, Johannesburg.

We welcome to the Society:-Mrs. D. Curnick, 73, Balmoral Drive, Durban North, and Miss M. Iuel, c/o Coronation Hospital, Johannesburg.

The Central Executive Committee has appointed Mrs. F. M. Rowe as its typist. She has already proved her immense value and we look forward to her continuing to work with us in the future.

The Journal Committee is happy to accept for its expenses donations of $£ 55 \mathrm{~s}$. Od. from the Natal Branch, and $f 117 \mathrm{~s}$. Od. from Mrs. D. Curnick.

The Constitution was accepted by Conference except for a few slight alterations, and is about to be printed, after which each member of the Society will receive a copy.

\section{MEDICAL AID SOCIETIES.}

The following travel rates have been accepted with effect from October 1st:-Five shillings for the first four Imiles, and one shilling and threepence per mile over and labove that distance.

\section{(Address to Congress, continued from page 5.)}

which will apply to the cure or relief of human ills the potent and fearful natural forces and energies uncovered and unleashed by modern Physical Research.

This then is the challenge to your Society and your Profession:

Firstly by research and study and interchange of knowledge to continue to establish your present practice on the soundest possible scientific basis; and secondly to be prepared for whatever the future may bring, to prove what is new, to adopt what is proven, to hold fast to what is sound and of good report, and to eschew what is shown to be false or outmoded.

With these words I wish you success in your deliberations. May they be of great value and profit to yourselves and your profession, and may the fruits thereof be manifest to the comfort and welfare of your patients. And, in confidence that this will be so, I have great pleasure in declaring the Conference open.
On Thursday, November 3rd, the Physical Medicine Section of the Medical Association invited Dr. H. Kessler of the Kessler Rehabilitation Institute, Newark, New Jersey, to talk and show his films on Rehabilitation. An invitation was kindly extended to physiotherapists, and it was a thoroughly enjoyable and worthwhile evening. Dr. Kessler is an excellent speaker and his films are some of the best seen in this country on rehabilitation.

Dr. Kessler was kind enough to lend some of them to the S.A.S.P. and they were shown to the Durban Branch in December. Unfortunately they have suddenly been recalled by Dr. Kessler, but it is hoped the Society may be able to borrow them and possibly others from him in the future.

\section{MISS SUSIE OOSTHUIZEN.}

In July 1955, Miss Susie Oosthuizen, our President, resigned from the Society.

For many years, Miss Oosthuizen had been an active member of the Society. She shouldered the burden of the Honorary General Secretaryship until 1952, and those of us who have worked with her on the many committees on which she served, fully appreciate her capabilities. In spite of her many commitments, she devoted much time and energy to furthering the interests of the Society, and frequently represented us on several bodies, including the National Council for the Care of Cripples.

It is largely due to her efforts that the Society enjoys its present status, and her valiant pioneering spirit will always be remembered.

Several years ago, the Avalon Rehabilitation Centre was transferred from the Cape to "Tussenkoppies," Miss Oosthuizen's farm, and she became its Superintendent. The advances and developments at the Centre have been considerable.

We are very pleased to know that although Miss Oosthuizen finds herself unable to work for the Society, she is continuing in the field of Physiotherapy. We thank her for her past endeavours and wish her every success in the future.

K.M.L.

\section{MISS HAZEL BAINES.}

The Society is very sorry to lose the services of Miss Hazel Baines, who has acted as General Secretary since October 1952.

Miss Baines first came to South Africa to take up a post as Electrotherapy lecturer on the staff of the University of the Witwatersrand. She was here for the whole of 1950 , then returned to England at the end of that year. She was back in South Africa in the middle of 1951, and has since become known to all of us, either personally, or nominally in her capacity as General Secretary.

The amount of work which that position entails has increased considerably since she took over from Miss Oosthuizen, and nothing but admiration and praise can be given for the way in which Miss Baines undertook the enormous task of acting as General Secretary when she was already kept very busy by her work at the University. She was efficient and capable at all times and her decision to return to England was a severe blow to the Society, by whom she will be greatly missed.

On behalf of the Society, Miss Baines was presented with a travelling case at a party given for her by the Central Executive Committee, at the house of Mrs. Molly Levy, kindly lent for the occasion.

We wish Miss Baines every success in the future and can assure her that all she has done for the Society will never be forgotten. 